\title{
STRUCTURAL, MORPHOLOGICAL AND THERMAL ANALYSIS OF SOME ALGINATE/STARCH/DELLITE HPS COMPOSITES FOR AQUEOUS Cu(II) REMOVAL
}

\author{
MARIA RÂPĂ, ECATERINA MATEI, ANDREEA ȚURCANU, ANDRA MIHAELA PREDESCU, \\ MIRCEA CRISTIAN PANTILIMON and CRISTIAN PREDESCU
}

\author{
Faculty of Material Science and Engineering, University Politehnica from Bucharest, \\ 313, Spl. Independentei, 060042 Bucharest, Romania \\ $₫$ Corresponding author: Andreea Țurcanu, andreea.turcanu90@yahoo.com
}

Received January 5, 2019

\begin{abstract}
The aim of the present paper is to investigate the properties of three binary systems based on $2 \%$ w/v sodium alginate $(\mathrm{AlgNa})$ and $3 \% \mathrm{w} / \mathrm{v}$ starch, prepared by means of a magnetic stirrer. 3\% w/v n-clay was added over the binary mixtures, while the amount of n-clay to all mixtures was $1.5 \%$ and $3 \%$, respectively. Microspheres were obtained by crosslinking the prepared mixtures with $1.5 \mathrm{M} \mathrm{CaCl}_{2} \cdot 2 \mathrm{H}_{2} \mathrm{O}$. The resulted composites were evaluated in terms of surface morphology (scanning electron microscopy - SEM), elemental composition (energy dispersive X-ray - EDX), swelling, thermal analysis (differential scanning calorimetry - DSC), electrochemical surface properties (zeta potential) and batch adsorption-desorption. The obtained results evidenced that the tested alginate/starch/n-clay 1/2/3 composite has the most promising properties for a biomaterial with potential applications in recovery of $\mathrm{Cu}$ (II) from polluted water.
\end{abstract}

Keywords: alginate, starch, n-clay, $\mathrm{Cu}(\mathrm{II})$ removal, swelling, point of zero charge, regeneration

\section{INTRODUCTION}

Copper $(\mathrm{Cu})$ is a metal occurring in the environment in three major valence states: copper metal $\left(\mathrm{Cu}^{0}\right), \mathrm{Cu}(\mathrm{I})$ and $\mathrm{Cu}(\mathrm{II}) . \mathrm{Cu}(\mathrm{II})$ is the most stable form. ${ }^{1} \mathrm{Cu}(\mathrm{II})$ is widely found in aquatic systems originating from both natural and anthropogenic sources. Natural sources of copper in aquatic systems include geological deposits, volcanic activity, weathering and erosion of rocks and soils. Anthropogenic sources of copper include mining activities, agriculture, metal and electrical manufacturing, as well as the use of pesticides. $^{2}$ It is used in the building industry for hot- and cold-water pipes, electrical wires, hose nozzles, and castings due to its malleability, ductility, and electrical conductivity properties. This metal is also used for the formation of haemoglobin and haemocyanin, the oxygentransporting pigments in the blood of vertebrates and shellfish, respectively. A considerable source of copper is represented by drinking water due to $\mathrm{Cu}$ leaching from plumbing. Copper concentrations that exceed $20 \mu \mathrm{g} \mathrm{g}^{-1}$ can be toxic for human and aquatic organisms and ecosystems. ${ }^{3}$ Therefore, treatment measures are necessary in order to prevent and reduce the exceeded levels of copper. Till now, various technologies have been developed to sequestrate $\mathrm{Cu}$ (II) from waters, such as chemical precipitation, ${ }^{4}$ ion exchange, ${ }^{5}$ adsorption, ${ }^{6,7}$ solvent extraction, ${ }^{8}$ membrane separation, ${ }^{9}$ and electrochemical methods. ${ }^{10}$ Among all the water treatment methods used to remove $\mathrm{Cu}$, adsorption is now recognized as the most attractive option, due to its simple operation, low investment, high potential recovery and reuse of metals and adsorbents.

Lately, numerous researches have been made in order to find inexpensive and effective adsorbents for $\mathrm{Cu}$ (II) removal. Examples of such adsorbents include: chitosan- $\mathrm{Fe}_{3} \mathrm{O}_{4}$ nanoparticles, ${ }^{11}$ amino-functionalized magnetic nanoparticles, ${ }^{12}$ carbon nanotube/calcium alginate composites, ${ }^{13}$ alginate-graphene oxide hybrid gel beads ${ }^{14}$ etc. Recently, it was reported that these nanomaterials can be combined with other environmental pollutants, increasing their toxicity. ${ }^{15}$ 
Currently, new environmentally friendly adsorbents for $\mathrm{Cu}(\mathrm{II})$ removal from aqueous solutions have attracted increased attention. Some of these natural materials that have been widely used for water purification include: clays, ${ }^{16-18}$ tree sawdust, ${ }^{19}$ algae,${ }^{20}$ silice, ${ }^{21}$ chitosan, ${ }^{22}$ starch, ${ }^{23,24}$ etc. Sodium alginate and clay hybrid composites are known for being used as adsorbents to remove the total organic acid anions, as a heat-stable salt from the industrial solvent methyl diethanolamine. ${ }^{25}$ Ely et al $^{26}$ have successfully encapsulated clay into alginate with the purpose to remove $\mathrm{Cu}$ (II). Tan et al. ${ }^{27}$ reported that immobilized bentonite clay into alginate led to a high sorption efficacy of $\mathrm{Cu}(\mathrm{II})$ adsorption (114.70 $\left.\mathrm{mg} \mathrm{g}^{-1}\right)$. This composite had a high reusability potential, with desorption throughout three consecutive adsorption-desorption cycles. It was found that the optimum conditions for adsorption are as follows: $\mathrm{pH}$ in the range of 4-5 and initial $\mathrm{Cu}$ (II) concentrations of $400 \mathrm{mg} \mathrm{L}^{-1}$.

These natural adsorbents present an attractive option due to their high abundance, relatively low cost, low carbon footprint and reduced environmental impact. ${ }^{25,28}$

The objectives of the present paper were to prepare adsorbent materials based on sodium alginate-starch-n-clay, in the form of microspheres, and to explore their properties in terms of surface morphology and particle size (SEM), elemental composition (EDX), swelling, thermal analysis (DSC) and electrochemical surface properties (zeta potential). It is expected that the developed material would serve as a new environmentally friendly adsorbent with the ability to remove $\mathrm{Cu}$ (II) from aqueous solutions.

\section{EXPERIMENTAL \\ Materials}

Sodium alginate salt $\left(\mathrm{C}_{6} \mathrm{H}_{7} \mathrm{O}_{6} \mathrm{Na}\right)_{n}$ supplied by BioChemica, has a molecular weight $10,000-600,000$ $\mathrm{g} / \mathrm{mol}$ and is characterized by purity of $90.8 \%$, heavy metals $(\mathrm{Pb})$ of max. $0.002 \%$, loss at drying of max. $15 \%, \mathrm{pH}$ (1\% water) $5.5-8.0,18-27 \%$ sulfated ash and $350-550 \mathrm{mPas}$ viscosity $\left(1 \%\right.$ at $\left.20^{\circ} \mathrm{C}\right)$. An aqueous solution of sodium alginate $(2 \mathrm{w} / \mathrm{v} \%)(\mathrm{AlgNa})$ was dissolved in distilled water by stirring at $90{ }^{\circ} \mathrm{C}$ for $4 \mathrm{~h}$ and at $200 \mathrm{rpm}$.

Starch $\left(\mathrm{C}_{6} \mathrm{H}_{10} \mathrm{O}_{5}\right)_{\mathrm{n}}$ supplied by Chimreactiv S.A. Bucharest, extracted from potato, is characterized by $50 \mathrm{~g} / \mathrm{L}$ solubility in water $\left(90^{\circ} \mathrm{C}\right), 6.0-7.5 \mathrm{pH}$ value ( $2 \%$ water), $0.7 \%$ reducing matter (maltose), and max. $10 \%$ drying loss $\left(105{ }^{\circ} \mathrm{C}\right)$. An aqueous solution of starch $(3 \mathrm{w} / \mathrm{v} \%)$ was prepared by means of a magnetic stirrer at $90{ }^{\circ} \mathrm{C}$ for 30 minutes.
Dellite HPS, hydrated aluminum silicate (n-clay), (Laviosa Chimica Mineraria S.P.A.) was used for preparing a solution containing 3\% of Dellite HPS in distilled water, by sonication for $1 \mathrm{~h}$.

$1.5 \mathrm{M}$ calcium chloride $\left(\mathrm{CaCl}_{2} \cdot 2 \mathrm{H}_{2} \mathrm{O}\right)$ was used as crosslinker.

Preparation of alginate/starch and nanoclay composite microspheres

Binary systems based on sodium alginate/gelatinized starch of $1: 1,1: 2$ and $2: 1 \mathrm{vol}$. ratios were obtained by dispersing $2 \%$ w/v sodium alginate (AlgNa) with 3\% w/v starch solution by means of a magnetic stirrer at $60{ }^{\circ} \mathrm{C}$ for $30 \mathrm{~min}$. The gelatinization process of starch means the disruption of molecular orderliness of starch molecules ${ }^{29}$ and was carried out according to the method previously described by F. Liu et al. ${ }^{28}$ To each binary mixture system, a solution of $1.5 \%$ and $3 \%$, respectively n-clay previously prepared was added. The codes and compositions of the prepared composites are shown in Table 1.

The solutions thus obtained were dripped with a syringe in a crosslinking bath containing $1.5 \mathrm{M}$ aqueous solution of $\mathrm{CaCl}_{2}$. Immediately upon contact with the crosslinking solution, spheres were formed. After $24 \mathrm{~h}$ of immersion in the crosslinking bath, the formed spheres were filtered and washed with distilled water, then dried at ambient temperature. Uniform spheres of approximately $3 \mathrm{~mm}$ were obtained. It was noticed that the obtained spheres became opaque and firmer after the introduction of n-clay in the composition. In order to determine the absorption of pollutants from wastewaters, the obtained microspheres were dried to completely remove interstitial water molecules.

\section{Investigation methods}

\section{Scanning electron microscopy (SEM)}

The morphology and structure of the materials were examined using a QUANTA 450 FEG scanning electron microscope, equipped with a field emission gun and a $1.2 \mathrm{~nm}$ resolution X-ray energy dispersive spectrometer, with a resolution of $133 \mathrm{eV}$. The specimens were gold sputtered prior to microscopy.

\section{Swelling index}

The weighed microspheres (w1) were immersed into water at $23{ }^{\circ} \mathrm{C}$ for $24 \mathrm{~h}$, and then they were removed, patted dry with tissue paper, and weighed again (with $0.1 \mathrm{mg}$ accuracy). The swelling index was determined using the following equation:

$\%$ Swelling index $=\frac{w_{2}-w_{1}}{W_{1}} \times 100$

where $W 2$ is the weight of swollen microspheres $(\mathrm{g})$ and $W 1$ is the weight of microspheres before swelling (g).

Three tests for each microsphere composition were performed, and the results were expressed as the mean value \pm standard deviation. 
Differential scanning calorimetry measurements (DSC)

DSC analyses were performed by means of a Mettler Toledo (Model DSC 823e, Switzerland) Calorimeter from $25{ }^{\circ} \mathrm{C}$ to $220{ }^{\circ} \mathrm{C}$, at a heating rate of $10^{\circ} \mathrm{C} / \mathrm{min}$. DSC curves were processed with the aid of STARe 9.10 software from Mettler-Toledo.

Point of zero charge $\left(\mathrm{pH}_{p z c}\right)$
The point of zero charge $\left(\mathrm{pH}_{\mathrm{pzc}}\right)$ of the prepared composites was measured by means of electrophoretic mobility (Zetasizer Nano, Malvern Instruments, UK), based on the dynamic light scattering (DLS) technique. The solution surface charge at the $\mathrm{pH}$ values ranging from 3 to 7 was evaluated using $1 \mathrm{mM} \mathrm{NaCl}$ or $1 \mathrm{mM}$ $\mathrm{HCl}$ to adjust the $\mathrm{pH}$. The $\mathrm{pH}_{\mathrm{pzc}}$ value was determined from a plot of initial $\mathrm{pH}$ versus $\mathrm{pH}$ of the samples.

Table 1

Coding and composition of samples

\begin{tabular}{llccc}
\hline \multirow{2}{*}{ System } & \multirow{2}{*}{ Sample code } & \multicolumn{3}{c}{ Composition } \\
\cline { 3 - 4 } System I & AlgNa/starch 1/1 & AlgNa, vol\% & Starch, vol\% & n-Clay, wt\% \\
\hline \multirow{3}{*}{ System II } & AlgNa/starch/n-clay 1/1/1.5 & 50 & 50 & - \\
& AlgNa/starch/n-clay 1/1/3 & 50 & 50 & 1.5 \\
& AlgNa/starch 1/2 & 33.33 & 66.66 & 3.0 \\
& AlgNa/starch/n-clay 1/2/1.5 & 33.33 & 66.66 & - \\
\multirow{2}{*}{ System III } & AlgNa/starch/n-clay 1/2/3 & 33.33 & 66.66 & 3.0 \\
& AlgNa/starch 2/1 & 66.66 & 33.33 & - \\
& AlgNa/starch/n-clay 2/1/1.5 & 66.66 & 33.33 & 1.5 \\
& AlgNa/starch/n-clay 2/1/3 & 66.66 & 33.33 & 3.0 \\
\hline
\end{tabular}

\section{Batch adsorption experiments}

Adsorption of $\mathrm{Cu}(\mathrm{II})$ was performed in the batch mode by shaking $500 \mathrm{mg}$ of adsorbent with $100 \mathrm{~mL}$ of $\mathrm{Cu}$ (II) solution, with the concentration of $2 \mathrm{mg} \mathrm{L}^{-1}$ at room temperature, for specific time intervals (maximum of $24 \mathrm{~h}$ ). The $\mathrm{pH}$ of the solutions was 6 . It is known that a precipitate of copper hydroxide will be produced at $\mathrm{pH}>5.8 .{ }^{13}$ After reaching equilibrium, the solutions were filtered (Whatman filter paper No. 1) and the $\mathrm{Cu}$ (II) concentration in the filtrate was detected at $\lambda=324.7 \mathrm{~nm}$ by an atomic absorption spectrometer (GBC 932 AB PLUS, from GBC Scientific Equipment PTY Ltd., Australia) with acetylene flame.

The $\%$ of $\mathrm{Cu}(\mathrm{II})$ removed from synthetic aqueous solutions was calculated using Equation (2):

$\% C u(I I)=\frac{\left(C_{0}-C_{2}\right)}{C_{0}} \times 100$

where $C_{\square}$ and $C_{1}$ are the initial and final $\mathrm{Cu}(\mathrm{II})$ concentration in the solution $(\mathrm{mg} / \mathrm{L})$ at the tested time.

\section{Desorption studies}

Desorption studies employed $0.1 \mathrm{M} \mathrm{HCl}$ solution. After the initial adsorption of $\mathrm{Cu}(\mathrm{II})$ containing $2 \mathrm{mg}$ $\mathrm{L}^{-1}$ of metal ions for $24 \mathrm{~h}$, the composites microspheres were immersed into $30 \mathrm{~mL}$ of $0.1 \mathrm{M}$ solution of $\mathrm{HCl}$. After removal of $\mathrm{Cu}$, the composites were gently washed with distilled water till no $\mathrm{Cl}$ ions were detected (checked with $\mathrm{AgNO}_{3}$ solution). Then, the adsorbents were again immersed into $100 \mathrm{~mL}$ of metal ion solution of $2 \mathrm{mg} \mathrm{L}^{-1}$ concentration at room temperature for $24 \mathrm{~h}$. The concentrations of the removed metal were analyzed by an atomic absorption spectrometer. This procedure was repeated twice. The amount of $\mathrm{Cu}$ ions adsorbed per unit weight of sorbent $\left(\mathrm{q}_{\mathrm{e}}\right)$ at equilibrium was calculated by Equation (3):

$q_{e}\left(m g \cdot g^{-1}\right)=\frac{\left(C_{0}-C_{q}\right) \times V}{m} \times 100$

where $C_{0}$ and $C_{e}$ are the concentration of the $\mathrm{Cu}$ (II) solution before absorption and after reaching adsorption equilibrium, respectively $\left(\mathrm{mg} \mathrm{L}^{-1}\right) ; V$ is the volume of adsorbate (L) and $m$ is the mass of absorbent (g).

\section{RESULTS AND DISCUSSION SEM and EDX}

SEM images of $\mathrm{AlgNa} / \mathrm{starch} / \mathrm{n}$-clay composites are shown in Figure 1 (a-i) and the energy dispersive X-ray (EDX) patterns of the composites are shown in Figure $2(\mathrm{a}-\mathrm{c})$.

The morphology examination revealed nonaggregated microspheres with irregular surfaces. The incorporation of $n$-clay led to a pronounced tendency of roughness, sphericity and porosity (Fig. 1). The largest surfaces (1.621-1.738 $\mathrm{mm}^{2}$ ) were obtained in the case of the composites containing a vol. ratio of $1 / 2$ of alginate/starch. By the addition of n-clay into the alginate/starch composites, the dimensions of the microspheres slowly increased. This is attributed to strong hydrogen bonds between sodium alginate and starch, as well as to $\mathrm{CaCl}_{2}$ crosslinking. 


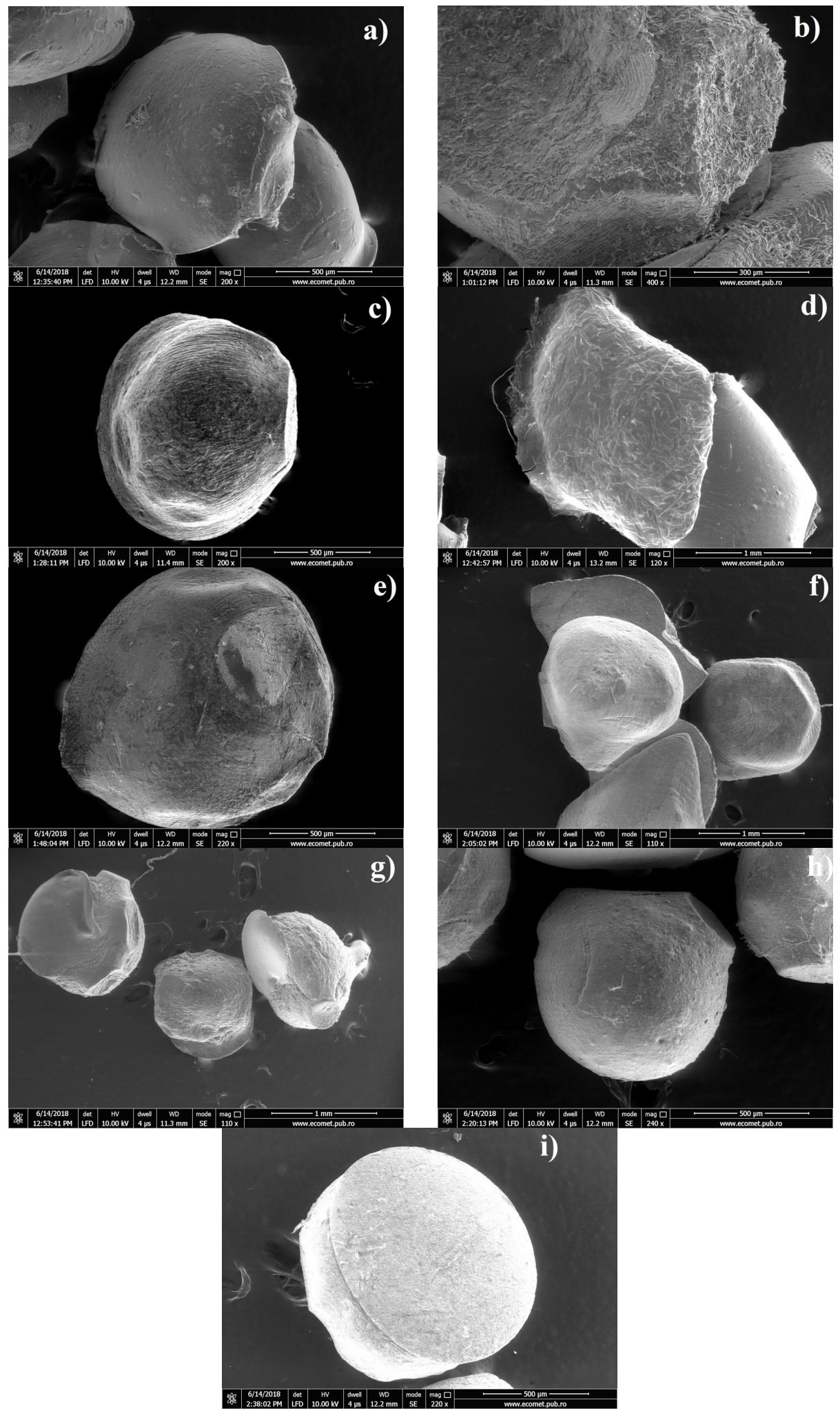

Figure 1: SEM micrographs of a) AlgNa/starch 1/1 (200x); b) AlgNa/starch/n-clay 1/1/1.5 (400x); c) AlgNa/starch/n-clay 1/1/3 (200x); d) AlgNa/starch 1/2 (120x); e) AlgNa/starch/n-clay 1/2/1.5 (220x); f) AlgNa/starch/n-clay 1/2/3 (110x); g) $\mathrm{AlgNa} / \operatorname{starch} 2 / 1$ (110x); h) AlgNa/starch/n-clay 2/1/1.5 (240x); i) AlgNa/starch/n-clay 2/1/3 (220x) 
Composites
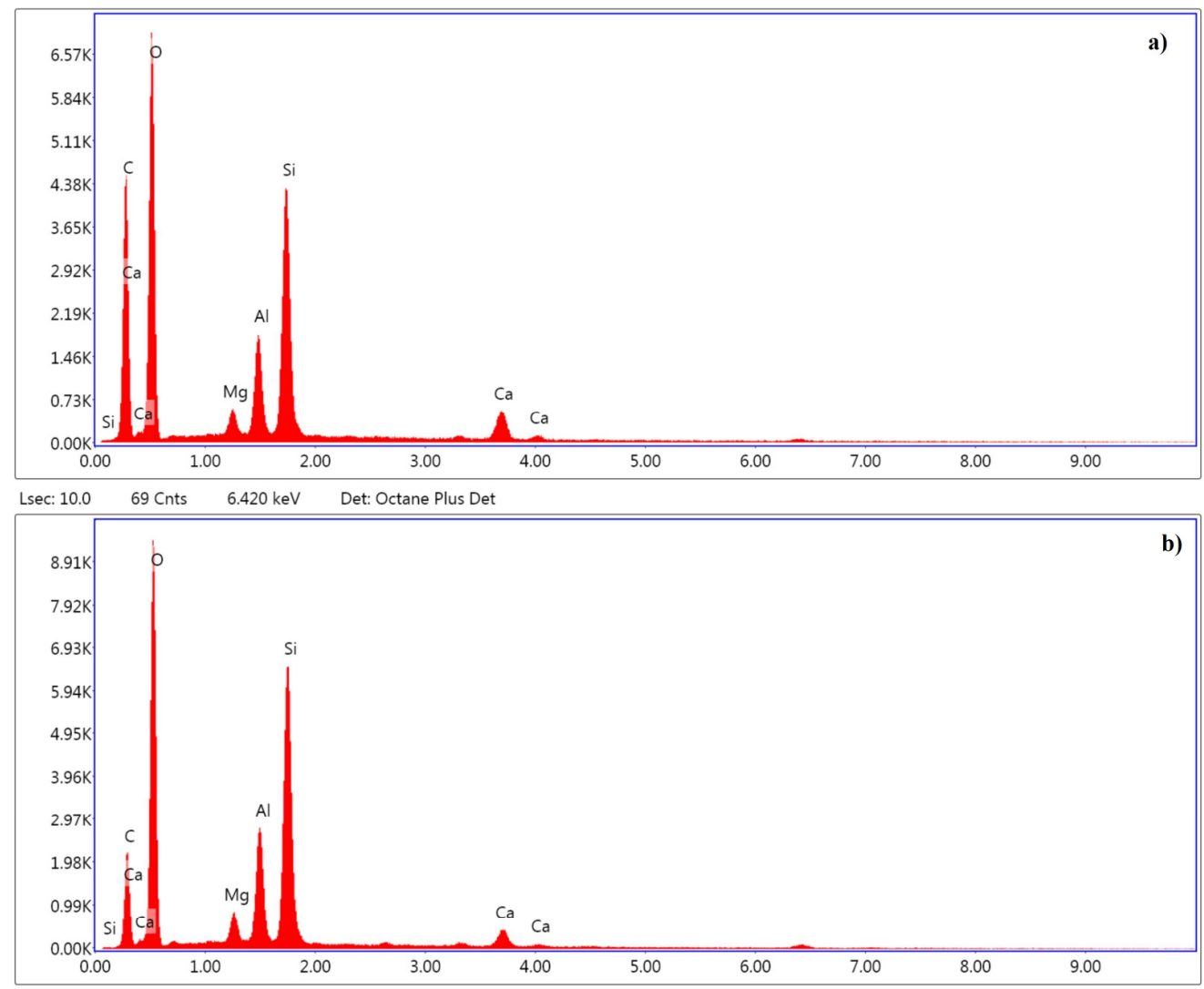

Lsec: $10.0 \quad 105$ Cnts $6.420 \mathrm{keV} \quad$ Det: Octane Plus Det

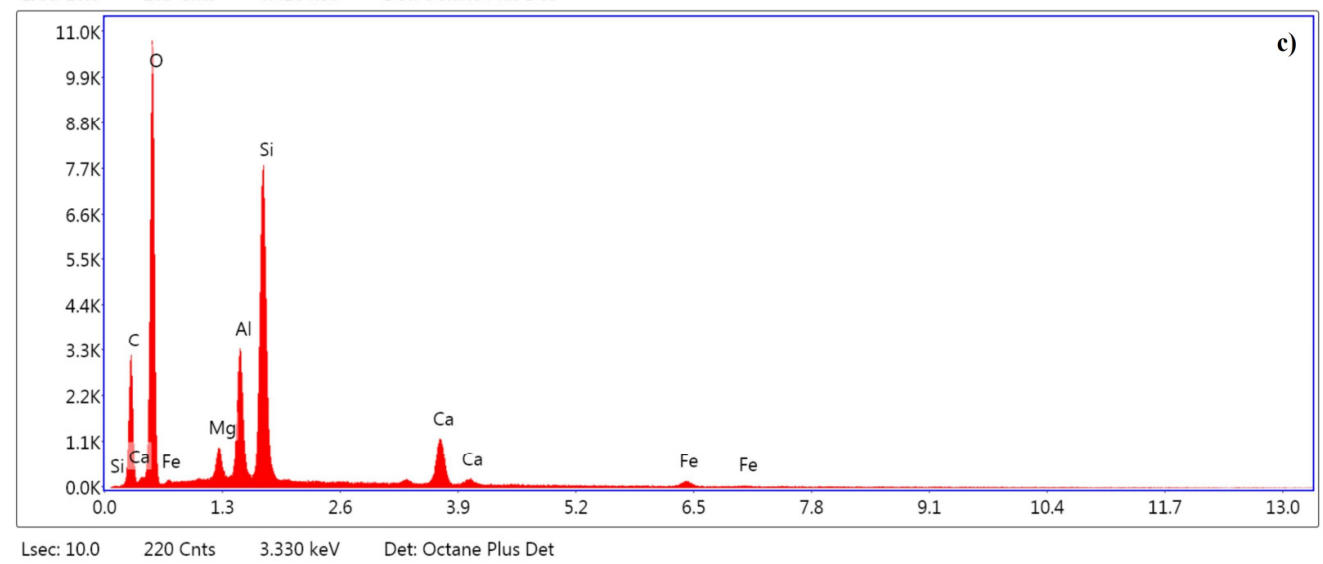

Figure 2: EDX spectra of a) AlgNa/starch/n-clay 1/1/3; b) AlgNa/starch/n-clay 1/2/3; c) $\mathrm{AlgNa} / \mathrm{starch} / \mathrm{n}$-clay $2 / 1 / 3$

The condensation reaction between the carboxyl groups of the calcium alginate and the hydroxyl groups found in the starch and n-clay facilitates the adsorption of metal ions by the alginate/starch/n-clay systems. It is expected the systems containing more starch to have a stabilizing effect, preventing their degradation. ${ }^{30}$
The energy dispersive X-ray (EDX) patterns of $\mathrm{AlgNa} / \mathrm{starch} / \mathrm{n}$-clay composites exhibit carbon content in the range of 26.25-39.72 $\mathrm{wt} \%$, oxygen in the range of 42.76-51.41 wt\%, aluminum of 3.75-6.06 wt\%, and silicate of 9.63-15.26 wt\%. The intense peaks of $\mathrm{Si}, \mathrm{Mg}$ and $\mathrm{Al}$ confirmed the presence of n-clays in the composite beads. Table 2 summarizes this EDX analysis. From Table 2, it 


\section{MATEI RÂPĂ et al.}

can be observed that $\mathrm{Mg}, \mathrm{Al}$ and $\mathrm{Si}$ were found in higher amounts in the composites containing an alginate:starch ratio of $1: 2$.

\section{Swelling behavior}

The behavior of the microspheres after immersion into water for $24 \mathrm{~h}$ is shown in Table 3. A gradual increase in the swelling index profile, with starch loading in the composites, is observed (Table 3). Maximal swelling is observed for System II (AlgNa/starch 1/2) and minimal swelling - for System III (AlgNa/starch 2/1). This behavior at swelling can be explained by the hydrophilicity of starch. ${ }^{31}$ The linear component (amylose) from the starch structure in contact with water forms networks to hold water molecules. ${ }^{32}$ Also, the interaction of reactive $-\mathrm{OH}$ groups from n-clays and starch with the reactive sites of alginate resulted in superabsorbent composites. $^{33}$ It is expected the increased interaction between water, starch and n-clay on the accessible surfaces of the beads to contribute to high adsorption of $\mathrm{Cu}(\mathrm{II})$.

\section{Differential scanning calorimetry measurements (DSC)}

The DSC curves shown in Figure 3 indicate a maximum endothermic peak around the temperature of $70{ }^{\circ} \mathrm{C}$ due to the evaporation of crystallization water. The degradation onset temperature occurred in the range of $184-206{ }^{\circ} \mathrm{C}$, 163-199 ${ }^{\circ} \mathrm{C}$ and $185-201{ }^{\circ} \mathrm{C}$ for the composites containing alginate/starch ratios of $1 / 1,1 / 2$ and $2 / 1$, respectively. Thermal analysis by DSC showed that the introduction of n-clay into binary systems had the effect of delaying degradation.

Table 2

Elemental composition of $\mathrm{AlgNa} / \mathrm{starch} / \mathrm{n}$-clay composites

\begin{tabular}{|c|c|c|c|c|c|c|}
\hline \multirow{3}{*}{ Elements } & \multicolumn{2}{|c|}{ AlgNa/starch/n-clay 1/1/3 } & \multicolumn{2}{|c|}{$\mathrm{AlgNa} / \mathrm{starch} /$ n-clay $1 / 2 / 3$} & \multicolumn{2}{|c|}{$\mathrm{AlgNa} /$ starch/n-clay $2 / 1 / 3$} \\
\hline & \multicolumn{6}{|c|}{ Concentration } \\
\hline & $\mathrm{wt}^{\mathrm{a}}$ & at ${ }^{\mathrm{b}}$ & $\mathrm{wt} \%$ & at\% & $\mathrm{wt} \%$ & at\% \\
\hline Carbon & 39.72 & 50.26 & 26.25 & 35.79 & 29.24 & 38.55 \\
\hline Oxygen & 42.76 & 40.61 & 48.46 & 49.59 & 51.41 & 50.89 \\
\hline Magnesium & 0.94 & 0.59 & 1.59 & 1.07 & 1.40 & 0.91 \\
\hline Aluminum & 3.75 & 2.11 & 6.06 & 3.68 & 4.47 & 2.62 \\
\hline Silicate & 9.63 & 5.21 & 15.26 & 8.90 & 10.25 & 5.78 \\
\hline Calcium & 3.19 & 1.21 & 2.37 & 0.97 & 2.97 & 1.17 \\
\hline Iron & - & - & - & - & 0.27 & 0.08 \\
\hline
\end{tabular}

Table 3

Swelling index for $\mathrm{AlgNa} / \mathrm{starch} / \mathrm{n}$-clay microsphere composites

\begin{tabular}{lc}
\hline Sample & Swelling index, $\%$ \\
\hline AlgNa/starch $1 / 1$ & $141.14 \pm 15.12$ \\
$\mathrm{AlgNa} /$ starch/n-clay $1 / 1 / 1.5$ & $110.82 \pm 10.42$ \\
$\mathrm{AlgNa} /$ starch/n-clay $1 / 1 / 3$ & $131.70 \pm 13.31$ \\
$\mathrm{AlgNa} /$ starch $1 / 2$ & $250.76 \pm 15.92$ \\
$\mathrm{AlgNa} / \mathrm{starch} / \mathrm{n}$-clay $1 / 2 / 1.5$ & $161.28 \pm 13.26$ \\
$\mathrm{AlgNa} / \mathrm{starch} / \mathrm{n}$-clay $1 / 2 / 3$ & $226.00 \pm 17.21$ \\
$\mathrm{AlgNa} /$ starch $2 / 1$ & $147.05 \pm 12.03$ \\
$\mathrm{AlgNa} /$ starch/n-clay $2 / 1 / 1.5$ & $114.64 \pm 10.78$ \\
$\mathrm{AlgNa} /$ starch/n-clay $2 / 1 / 3$ & $86.98 \pm 6.62$ \\
\hline
\end{tabular}

\section{Determination of $\mathrm{pH}_{\mathrm{pzc}}$}

The behavior of the composites in the $\mathrm{pH}$ range from 1 to 7 is plotted in Figure 4. The stability tests carried out indicated a general dissolution tendency in aqueous media up to $\mathrm{pH} \leq$
4. For the composites containing alginate/starch in ratios of $1 / 1$ and $2 / 1$, the dissolution trend is observed in the entire $\mathrm{pH}$ range. As the $\mathrm{pH}$ decreased, the surface of the alginate/starch/nclay exhibited an increasingly positive 
characteristic, which is not favorable for $\mathrm{Cu}(\mathrm{II})$ adsorption. At lower $\mathrm{pH}, \mathrm{Cu}(\mathrm{II})$ is present in solutions as a free cation $\left(\mathrm{Cu}^{2+}\right.$ and $\left.\mathrm{CuOH}^{+}\right)$, which can compete with protons for the surface binding sites. ${ }^{34}$ In the case of the composite containing an alginate/starch ratio of $1 / 2$ (System II), a more stable behavior up to $\mathrm{pH} 7$ is observed. Other studies also reported that $\mathrm{Cu}(\mathrm{II})$ adsorption increased as the solution $\mathrm{pH}$ increased. ${ }^{5,6}$


Figure 3: DSC curves of AlgNa/starch/n-clay; a) System I ( 1 - AlgNa/starch 1/1; 2 - AlgNa/starch/n-clay 1/1/1.5; 3 $\mathrm{AlgNa} / \mathrm{starch} / \mathrm{n}$-clay 1/1/3); b) System II (1 - AlgNa/starch 1/2; 2 - AlgNa/starch/n-clay 1/2/1.5; 3 - AlgNa/starch/n-clay 1/2/3); c) System III (1 - AlgNa/starch 2/1; 2 - AlgNa/starch/n-clay 2/1/1.5; 3 - AlgNa/starch/n-clay 2/1/3)

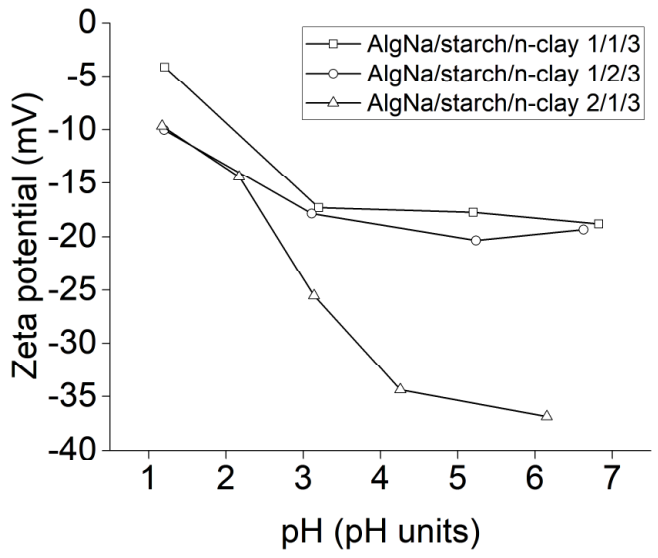

Figure 4: $\mathrm{pH}_{\mathrm{pzc}}$ of $\mathrm{AlgNa} / \mathrm{starch} / \mathrm{n}$-clay composites 


\section{Adsorption of $\mathrm{Cu}(\mathrm{II})$}

The efficiency of adsorption (\%) for alginate/starch/n-clay microspheres after $24 \mathrm{~h}$ contact time with $2 \mathrm{mg} \mathrm{L}^{-1}$ concentration of $\mathrm{Cu}$ (II) is plotted in Figure 5. From Figure 5, it can be observed that the adsorption capacity depends on the composition of the absorbents. Thus, System I containing a 1/1 ratio of alginate/starch exhibited higher affinity to $\mathrm{Cu}(\mathrm{II})$ pollutant than System II (alginate/starch ratio of $1 / 2$ ) and System III (alginate/starch ratio of 2/1), showing 38\%, 10\% and $4 \%$, respectively, removal of the pollutant after $2 \mathrm{~h}$. High removal efficiencies were recorded by the binary systems after $24 \mathrm{~h}$ of contact with the contaminant solution. In the case of System I, which incorporated n-clay, it is observed that the adsorption slowly decreased compared with the adsorption efficiency of $\mathrm{AlgNa} / \mathrm{starch} 1 / 1$ (Fig. 5a). In the case of alginate/starch $2 / 1$ adsorbent (System III), the increase of the carboxyl groups led to an unsaturation of the active adsorption sites due to $\mathrm{Cu}$ (II) deficiency (Fig. 5c). Thus, it is possible to use n-clay as a filler, as it reduces the internal surface area of accessible microspheres.

The incorporation of n-clay into System II led to an improved adsorption of $\mathrm{Cu}$ (II). $\mathrm{AlgNa} / \mathrm{starch} / \mathrm{n}$-clay $1 / 2 / 3$ adsorbent showed the highest removal capacity (95\% after $24 \mathrm{~h}$ ), followed by $\mathrm{AlgNa} / \mathrm{starch} / \mathrm{n}$-clay $1 / 1 / 3$ adsorbent (82\%) and $\mathrm{AlgNa} / \mathrm{starch} / \mathrm{n}$-clay $2 / 1 / 3$ adsorbent (76\%). With increasing the starch and n-clay concentrations, it can be assumed that the adsorption active sites on alginate/starch/n-clay $1 / 2 / 3$ adsorbent increased, so that the pollutant uptake is favored (Fig. 5b).

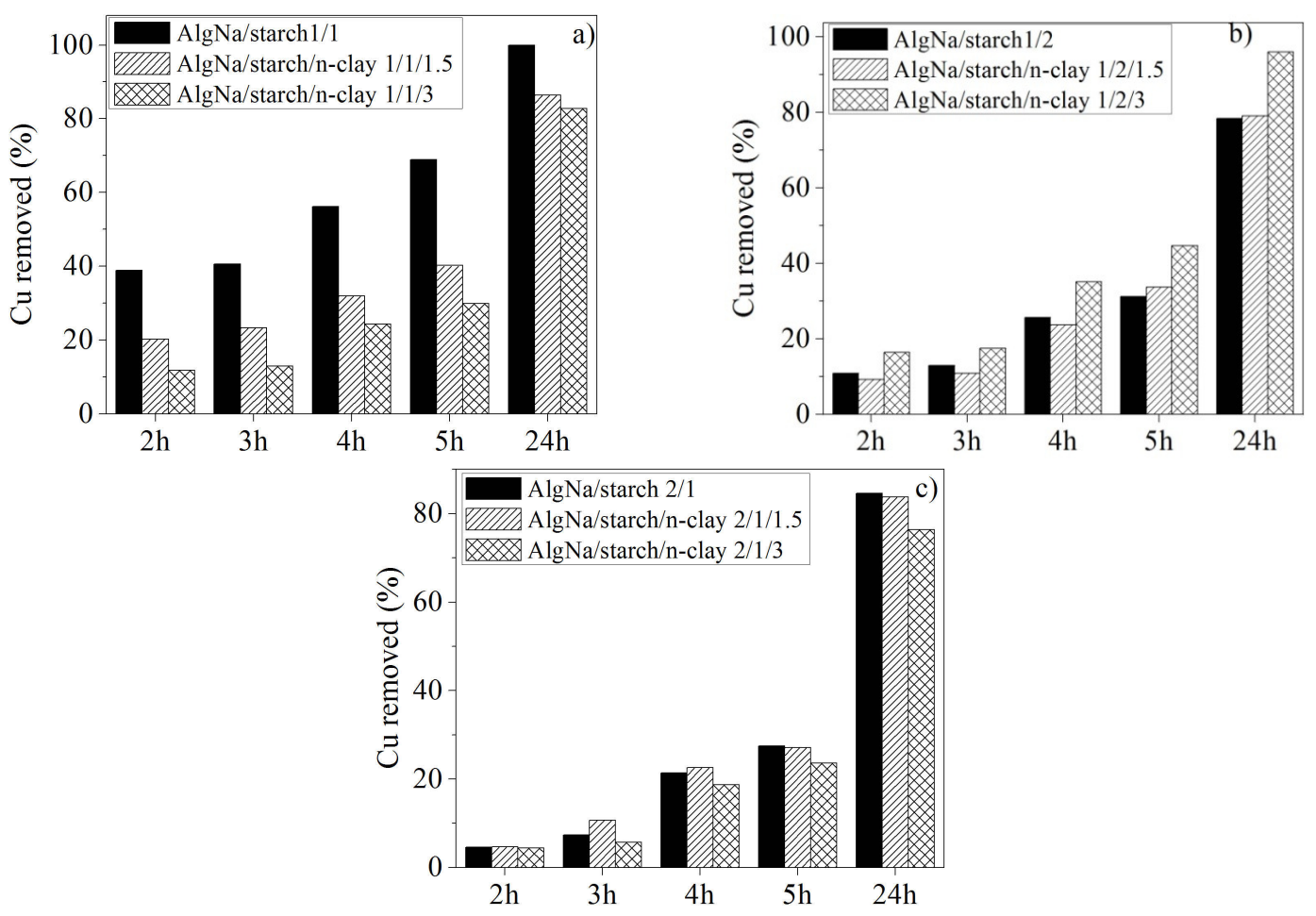

Figure 5: Efficiency of $\mathrm{Cu}(\mathrm{II})$ adsorption (\%) by $\mathrm{AlgNa} / \mathrm{starch} / \mathrm{n}$-clay systems; a) System I (AlgNa/starch/n-clay with $1 / 1$ ratio of alginate/starch); b) System II (AlgNa/starch/n-clay with $1 / 2$ ratio of alginate/starch); c) System III (AlgNa/starch/n-clay with $2 / 1$ ratio of alginate/starch). Experimental conditions: $0.5 \mathrm{~g} \mathrm{AlgNa} / \mathrm{starch} / \mathrm{n}-\mathrm{clay}$ microspheres dispersed in $100 \mathrm{~mL}$ of copper (II) at concentrations of $2 \mathrm{mg} \mathrm{L}^{-1}$ for maximum $24 \mathrm{~h}$ 


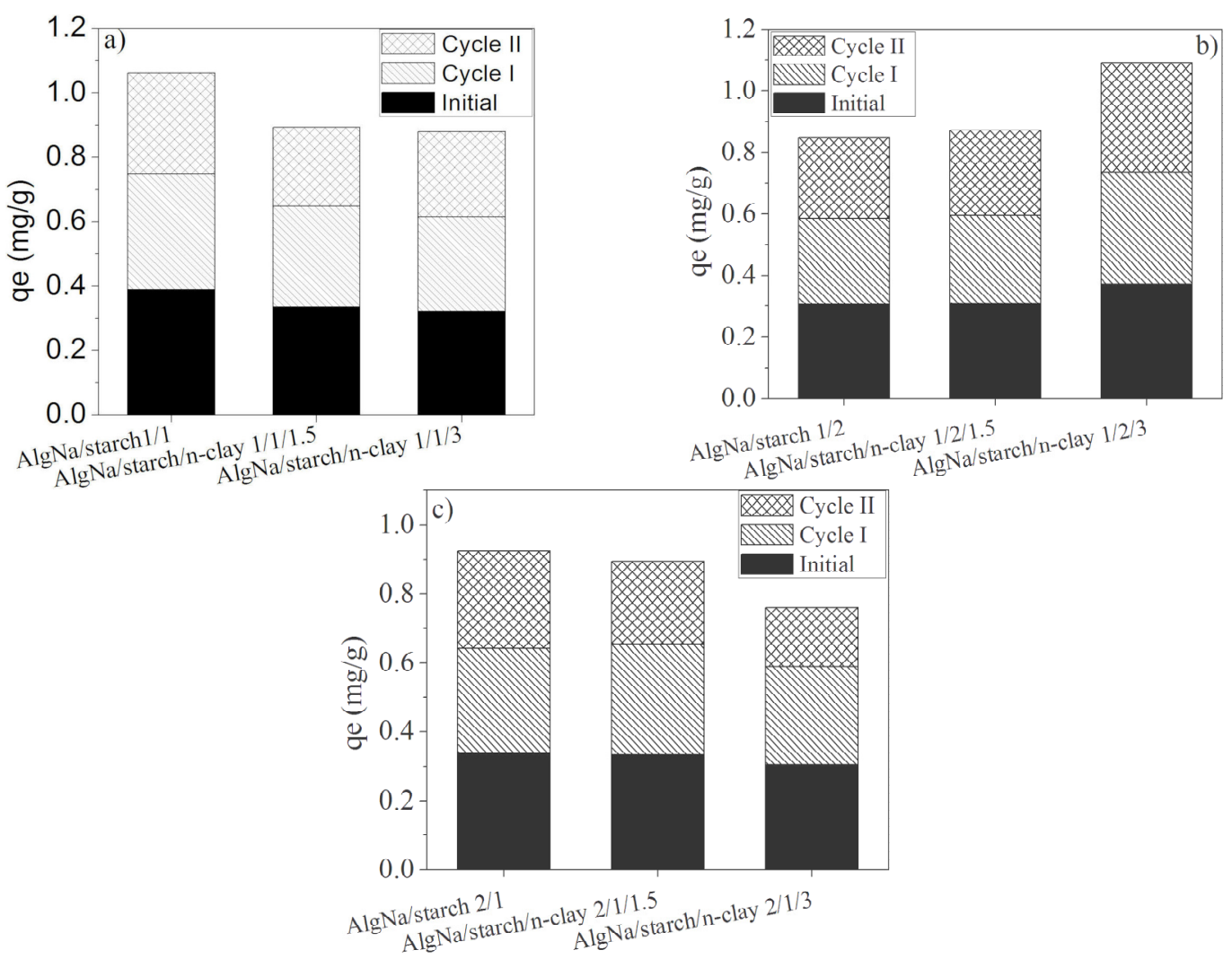

Figure 6: Reutilization of $\mathrm{AlgNa} / \mathrm{starch} / \mathrm{n}$-clay microspheres for $\mathrm{Cu}(\mathrm{II})$ removal during two cycles; a) System I; b) System II; c) System III. Experimental conditions: $0.5 \mathrm{~g} \mathrm{AlgNa/starch/n-clay} \mathrm{microspheres} \mathrm{containing} \mathrm{Cu(II)} \mathrm{adsorbed}$ for $24 \mathrm{~h}$, kept in contact with $0.1 \mathrm{M} \mathrm{HCl}$, washed with distilled water and then immersed into $100 \mathrm{~mL}$ of pollutant in concentration of $2 \mathrm{mg} \mathrm{L}^{-1}$ for $24 \mathrm{~h}$

This result is correlated with the swelling behavior of $\mathrm{AlgNa} / \mathrm{starch} / \mathrm{n}$-clay $1 / 2 / 3$ adsorbent Table 3 and $\mathrm{pH}_{\mathrm{pzc}}-$ Figure 4. Around $\mathrm{pH}$ 6, the alginate, starch and n-clay exhibited a significant amount of negative charges due to the deprotonated carboxyl and hydroxyl groups. These negative charges allowed the polysaccharides to induce repulsive electrostatic forces, causing both swelling and interaction with positively charged ionic groups. These results are in agreement with those reported by other authors. ${ }^{14,16,22}$

\section{Desorption study}

According to the experiments carried out in this study, maximum adsorption of $\mathrm{Cu}$ (II) was considered after $24 \mathrm{~h}$. The regeneration of the adsorbent systems was examined by reusing twice the alginate/starch/n-clay microspheres of different compositions. Thus, after the microspheres were treated with $0.1 \mathrm{M}$ solution of $\mathrm{HCl}$ in order to remove the retained $\mathrm{Cu}(\mathrm{II})$, the adsorption/desorption tests were performed in order to record the amount of adsorbate adsorbed per unit weight of sorbent $\left(\mathrm{q}_{\mathrm{e}}\right)$. The obtained results, in comparison with those before desorption, are shown in Figure $6(\mathrm{a}, \mathrm{b}, \mathrm{c})$.

From Figure 6, it is observed that the $\mathrm{AlgNa} / \mathrm{starch} /$ n-clay microspheres show a decrease of the amount of pollutant retained by about $10 \%$ after each regeneration cycle. The highest $\mathrm{q}_{\mathrm{e}}$ was found for System II (containing 1/2 ratio of alginate/starch and 3\% n-clay) -0.3624 $\mathrm{mg} \mathrm{g}^{-1}$ and $0.3546 \mathrm{mg} \mathrm{g}^{-1}$ after the first and second regeneration, respectively. System I (AlgNa/starch 1/1) and System II (AlgNa/starch 2/1) showed a decreased amount of metal on the adsorbent; the increased n-clay amount was explained by the dissolution behavior $\left(\mathrm{pH}_{\mathrm{pzc}}-\right.$ Fig. 4). Alg/Na/starch/n-clay $1 / 1 / 3$ showed $\mathrm{q}_{\mathrm{e}}$ values of $0.2924 \mathrm{mg} \mathrm{g}^{-1}$ and $0.2662 \mathrm{mg} \mathrm{g}^{-1}$, while $\mathrm{AlgNa} / \mathrm{starch} / \mathrm{n}$-clay $2 / 1 / 3$ recorded $\mathrm{q}_{\mathrm{e}}$ values of $0.2846 \mathrm{mg} \mathrm{g}^{-1}$ and $0.1712 \mathrm{mg} \mathrm{g}^{-1}$ after the first and second regeneration, respectively.

This regeneration study demonstrates the economic efficiency of the alginate/starch/n-clay 
1/2/3 adsorbent. Successful adsorption-desorption cycles were found for modified chitosan used for the removal of $\mathrm{Cu}(\mathrm{II})$ ions from aqueous medium. $^{22,35}$ The sorption performance of heavy metal ions was also reported for other cheap and widely available adsorbents, such as chitosan/poly(vinyl amine), ${ }^{36}$ hemp fibers, ${ }^{37}$ lignin, ${ }^{38}$ thiol-functionalized cellulose, ${ }^{39}$ etc. Therefore, removing $\mathrm{Cu}$ contaminants from waste waters with adsorbent materials made from abundant and inexpensive polysaccharides, with tailored composition, could be a feasible approach to tackle the pollution problem.

\section{CONCLUSION}

Binary systems from alginate/starch with different vol. ratios $(1 / 1,1 / 2$ and $2 / 1$, respectively), loaded with 1.5 and $3 \%$ n-clay, were prepared and tested as possible sorbents for $\mathrm{Cu}$ (II) removal from waste water.

From SEM images, it was observed that the microspheres did not exceed $2 \mathrm{~mm}$ and the incorporation of n-clay led to a pronounced tendency of roughness, sphericity and porosity. The EDX analysis of the composites indicated intense peaks of $\mathrm{Si}, \mathrm{Mg}$ and $\mathrm{Al}$, due to the presence of n-clays in the composites. Elemental distribution was in the following range: carbon 26.25-39.72 wt\%, oxygen 42.76-51.41 wt\%, aluminum 3.75-6.06 wt\%, silicate 9.63-15.26 wt\%. It was established that the $\mathrm{AlgNa} / \mathrm{starch} / \mathrm{n}$ clay $1 / 2 / 3$ composite showed the highest adsorption of $\mathrm{Cu}$ (II) due to increased interactions between water molecules, starch and n-clay on the accessible surfaces of the beads. From the $\mathrm{pH}_{\mathrm{pzc}}$, it was observed that the composites containing the $1 / 1$ and $2 / 1$ ratios of alginate and starch had the tendency to dissolve at $\mathrm{pH}$ values lower than 4 . $\mathrm{AlgNa} /$ starch/n-clay $1 / 2 / 3$ was considered a more stable system. From the DSC curves, it was found that n-clay had the role of delaying the degradation temperature of the $\mathrm{AlgNa} / \mathrm{starch}$ systems. The incorporation of n-clay into adsorbent compositions had different effects on their adsorbent properties: for the alginate/starch binary systems $1 / 1$ and $2 / 1$ it acted as a filler, reducing the internal surface area of accessible microspheres to remove the cation, while in the case of alginate/starch $1 / 2$, it contributed to the highest removal capacity (95\% after $24 \mathrm{~h})$. The highest amount of $\mathrm{Cu}(\mathrm{II})$ adsorbed per unit weight of sorbent $\left(\mathrm{q}_{\mathrm{e}}\right)$ was found for System II (containing a $1 / 2$ alginate/starch ratio and 3\% n- clay) $-0.3624 \mathrm{mg} \mathrm{g}^{-1}$ and $0.3546 \mathrm{mg} \mathrm{g}^{-1}$ after the first and second regeneration, respectively.

The obtained results evidenced that the tested alginate/starch/n-clay composite, with the ratio of $1 / 2 / 3$ between the components, can be a promising biomaterial with potential applications in recovery of $\mathrm{Cu}(\mathrm{II})$ pollutant from aqueous systems.

ACKNOWLEDGMENTS: This work was supported by a grant of the Romanian Ministry of Research and Innovation, CCCDI-UEFISCDI, project number 26 PCCDI/01.03.2018, "Integrated and sustainable processes for environmental clean-up, wastewater reuse and waste valorization" (SUSTENVPRO), within PNCDI III and POC Program within Project number 49/2016, ID P_37_649 "Econanotechnologies for water treatment and wastes re-use".

\section{REFERENCES}

1 https://www.nap.edu/read/9782/chapter/3\#11

2 https://www.epa.gov/wqc/aquatic-life-criteriacopper

H. B. Bradl, in "Heavy Metals in the Environment: Origin, Interaction and Remediation", edited by H. B. Bradl, Elsevier Academic Press, 2005, pp. 1-282, https://www.elsevier.com/books-and-

journals/academic-press

4 L. K. Wang, D. A. Vaccari, Y. Li and N. K. Shammas, in "Handbook of Environmental Engineering", edited by L. K. Wang, Y. T. Hung and N. K. Shammas, Humana Press, 2005, pp. 141-197, https://www.springer.com/humana

5 Y. Chen, B. Pan, H. Li, W. Zhang, L. Lv et al., Environ. Sci. Technol., 44, 3508 (2010), https://doi.org/10.1021/es100341x

6 D. W. O'Connell, C. Birkinshaw and T. F. O’Dwyer, J. Appl. Polym. Sci., 99, 2888 (2006), https://doi.org/10.1002/app.22568

7 E. Matei, C. Predescu, A. Badanoiu, A. Predescu and D. Ficai, EEMJ, 14, 1001 (2015), http://www.eemj.icpm.tuiasi.ro/pdfs/vol14/no5/4_202_ Matei_12.pdf

8 J. C. Lee, T. Zhu, M. K. Jha, S. K. Kim, K. K. Yoo et al., Sep. Purif. Technol., 62, 596 (2008), https://doi.org/10.1016/j.seppur.2008.03.007

9 F. Gao, X. Du, X. Hao, S. Li, X. An et al., Chem. Eng. J., 328, 293 (2017), https://doi.org/10.1016/j.cej.2017.06.177

10 A. Yaqub, H. Ajab, S. Khan, S. Khan and R. Farooq, Water Qual. Res. J. Can., 44, 183 (2009), https://doi.org/10.2166/wqrj.2009.020

11 Y. C. Chang and D. H. Chen, J. Colloid Interface Sci., 283, $446 \quad$ (2005), https://doi.org/10.1016/j.jcis.2004.09.010 
12 Y. M. Hao, C. Man and Z. B. Hao, J. Hazard. Mater., $\quad \mathbf{1 8 4}, \quad 392 \quad$ (2010), https://doi.org/10.1016/j.jhazmat.2010.08.048

13 Y. Li, F. Liu, B. Xia, Q. Du, P. Zhang et al., J. Hazard. Mater., 177, $876 \quad$ (2009), https://doi.org/10.1016/j.jhazmat.2009.12.114

14 W. M. Algothmi, N. M. Bandaru, Y. Yu, J. G. Shapter and A. V. Ellis, J. Colloid Interface Sci., 397, 32 (2013), https://doi.org/10.1016/j.jcis.2013.01.051

15 Y. Liu, Y. Nie, J. Wang, J. Wang, X. Wang et al., Ecotoxicol. Environ. Saf., 162, 92 (2018), https://doi.org/10.1016/j.ecoenv.2018.06.079

16 K. G. Bhattacharyya and S. S. Gupta, Sep. Purif. Technol., $\quad 50, \quad 388 \quad$ (2006), https://doi.org/10.1016/j.seppur.2005.12.014

17 K. G. Bhattacharyya and S. S. Gupta, Desalination, 272, 66

(2011), https://doi.org/10.1016/j.desal.2011.01.001

18 M. A. Stylianou, V. J. Inglezakis, K. G. Moustakas, S. P. Malamisa and M. D. Loizidou, Desalination, 215, 133 (2007), https://doi.org/10.1016/j.desal.2006.10.031 19 A. Ahmad, M. Rafatullah, O. Sulaiman, M. H. Ibrahim, Y. Y. Chii et al., Desalination, 247, 636 (2009), https://doi.org/10.1016/j.desal.2009.01.007

20 Y. Nuhoglu, E. Malkoc, A. Gürses and N. Canpolat, Bioresour. Technol., 85, 331 (2002), https://doi.org/10.1016/S0960-8524(02)00098-6

21 X. Xue and F. Li, Micropor. Mesopor. Mater., 116, 116 (2008), https://doi.org/10.1016/j.micromeso.2008.03.023

22 B. Kannamba, K. L. Reddy and B. V. AppaRao, J. Hazard. Mater., 175, $939 \quad$ (2010), https://doi.org/10.1016/j.jhazmat.2009.10.098

23 D. V. Tarabukin, M. A. Torlopov, T. N. Shchemelinina, E. M. Anchugova, N. N. Shergina et al., J. Biotechnol., 260, $31 \quad$ (2017), https://doi.org/10.1016/j.jbiotec.2017.08.024

24 P. Li, B. Gao, A. Li and H. Yang, Micropor. Mesopor. Mater., 263, $210 \quad$ (2018), https://doi.org/10.1016/j.micromeso.2017.12.025

25 A. A. Edathil, P. Pal and F. Banat, Appl. Clay Sci., 156, 213

(2018), https://doi.org/10.1016/j.clay.2018.02.015

26 A. Ely, M. Baudu, M. O. Kankou and J. P. Basly, Chem. Eng. J., 178, 168 (2011), https://doi.org/10.1016/j.cej.2011.10.040
27 W. S. Tan and A. S. Y. Ting, Bioresour. Technol., 160 115

(2014), https://doi.org/10.1016/j.biortech.2013.12.056

28 F. Liu, B. Qin, L. He and R. Song, Carbohyd. $\begin{array}{llll}\text { Polym., } & \mathbf{7 8}, & 146 & \text { (2009), }\end{array}$ https://doi.org/10.1016/j.carbpol.2009.03.021

29 Q. Liu, E. Donner, R. Tarn, J. Singh and H. J. Chung, "Advances in Potato Chemistry and Technology", edited by J. Singh and L. Kaus, Academic Press, San Diego, 2009, p. 221

30 M. Li, T. Elder and G. Buschle-Diller, Polym. Bull., 74, 1267 (2016), https://doi.org/10.1007/s00289-016-1776-2

31 D. Dimonie, M. Petrache, C. Damian, L. Anton, M. Musat et al., Int. J. Polym. Sci., ID 7873120, (2016), https://doi.org/10.1155/2016/7873120

32 J. Malakar, A. K. Nayak and A. Das, Starch, 65, 603 (2013), https://doi.org/10.1002/star.201200231

33 A. Pourjavadi, H. Ghasemzadeh and R. Soleyman, J. Appl. Polym. Sci., 105, 2631 (2007), https://doi.org/10.1002/app.26345

34 Q. Q. Zhong, Q. Y. Yue, Q. Li, B. Y. Gao and X. $\mathrm{Xu}, \quad$ Carbohyd. Polym., 111, 788 (2014), https://doi.org/10.1016/j.carbpol.2014.05.043

35 M. V. Dinu, I. A. Dinu, M. M. Lazar and E. S. Dragan, Cellulose Chem. Technol., 52, 181 (2018), http://www.cellulosechemtechnol.ro/pdf/CCT34(2018)/p.181-192.pdf

36 A. I. Cocarta, V. Gutanu and E. S. Dragan, Cellulose Chem. Technol., 49, 775 (2015), http://www.cellulosechemtechnol.ro/pdf/CCT910(2015)/p.775-782.pdf

37 L. Tofan, C. Paduraru, C. Teodosiu and O. Toma, Cellulose Chem. Technol., 49, 219 (2015), http://www.cellulosechemtechnol.ro/pdf/CCT2(2015)/ p.219-229.pdf

8 B. Berrima, W. Maatar, G. Mortha, S. Boufi, L. E. Aloui et al., Cellulose Chem. Technol., 50, 701 (2016), http://www.cellulosechemtechnol.ro/pdf/CCT56(2016)/p.701-709.pdf

39 Z. Zhang, Y. Cao, L. Chen and Z. Huang, Cellulose Chem. Technol., 51, $559 \quad$ (2017), http://www.cellulosechemtechnol.ro/pdf/CCT56(2017)/p.559-567.pdf 